\title{
Small Radial Line Slot Array (RLSA) Antennas for Wi-Fi 5.8 GHz Devices
}

\author{
Teddy Purnamirza ${ }^{1}$, Imran M. Ibrahim ${ }^{2}$, Puji Prowadi ${ }^{1}$, Fitri Amillia ${ }^{1}$
}

\begin{abstract}
This paper presents a brief review of the development of small radial line slot array (RLSA) antennas for Wi-Fi devices. Based on the review, we concluded that some of the RLSA antennas designed and implemented on Wi-Fi devices are not optimal. Hence, this study aimed to design a small RLSA antenna for point-to-point $5.8 \mathrm{GHz}$ Wi-Fi devices with an optimum design using a previously developed technique known as the extreme beamsquint technique. We used this technique to design and simulate 50 small RLSA antenna models, and then we fabricated the best model. We measured the performance of the fabricated prototype to verify the simulation results. The following measurement results were obtained: a gain of $17.28 \mathrm{dBi}$, a bandwidth of $1 \mathrm{GHz}, \mathrm{a}$ beamwidth of $30^{\circ}$, and a mainlobe-to-sidelobe ratio of $10 \mathrm{~dB}$. These results meet the required antenna specifications for Wi-Fi devices. Moreover, the prototype was successfully tested as an antenna for a Wi-Fi device. Copyright () 2017 Praise Worthy Prize S.r.l. - All rights reserved.
\end{abstract}

Keywords: RLSA, Extreme Beamsquint Technique, Wi-Fi Devices, Small Antennas

\section{Introduction}

Radial line slot array (RLSA) antennas were first developed for satellite communications, but they have a diameter of about $650 \mathrm{~mm}$ [1]-[3]. Because RLSA antennas have a flat array and high efficiency [2]-[4], researchers have tried to use them in Wi-Fi devices [5][14]. It is well known that antennas for Wi-Fi devices are much smaller than antennas for satellites [31]-[33]. A problem was identified when researchers realized that small RLSA antennas have a high reflection coefficient due to an insufficient number of slots [14]-[16].

Small RLSA antennas were initially developed by Hirokawa [15]. Hirokawa used the matching slot pair technique to reduce the remaining power at the perimeter of small RLSA antennas in order to minimize the reflection coefficient. Akiyama also used the same technique [17], [18]. However, based on our observation, the matching slot pair technique is only used to radiate the remaining power at the antenna perimeter; it does not contribute to antenna gain.

Zagriatski used long slots to increase the ability of the slots to radiate power in order to reduce the remaining power at the perimeter of small RLSA antennas and, thus, reduce the reflection coefficient [11]. However, based on our observation, while this method can reduce the reflection coefficient, it can also decrease the antenna gain because long slots cannot radiate the focused power.

Imran introduced a $5.8 \mathrm{GHz}$ RLSA antenna with a gain of $26 \mathrm{dBi}$ and successfully used it as an antenna for point-to-point links [19]-[21]. This design utilized the beamsquint technique, which is the same technique used to design RLSA antennas for satellite applications.

Hence, the $650 \mathrm{~mm}$ diameter of this antenna is still too large to be applicable for small Wi-Fi devices.

Several other researchers have reported on the design of small RLSA antennas using FR4 materials [22],[23].

However, the antennas in those studies were not designed correctly; they had overlap slots and a cavity of antennas that consisted of several FR4 layers stuck together using glue, and they used high loss materials such as FR4. These mistakes resulted in low gain and high reflection coefficients.

Purnamirza reported on a small three-layer RLSA antenna, which consists of a polypropylene layer and two FR4 layers [13]. Although this antenna used affordable FR4 material, the fabrication was more complex because the three layers need to be aligned accurately.

Based on our knowledge, since 2012 no studies have reported on using small RLSA antennas for Wi-Fi pointto-point applications. Several papers that were published after 2012 only discussed the theory of RLSA antennas [24]-[30].

In 2012, we presented a simple technique (extreme beamsquint) that effectively reduces the reflection coefficient of small RLSA antennas [14]. As a continuation of that study, the present paper reports on using the simple technique we developed, which is an RLSA antenna that has the potential to be suitable for use in Wi-Fi devices. The development of this antenna began by studying the antenna specifications used by point-topoint Wi-Fi devices, including gain, beamwidth, and bandwidth, as detailed in Section II. Based on these specifications, we designed and fabricated an RLSA antenna using the extreme beamsquint technique. We then measured the fabricated antenna and tested its use in Wi-Fi devices. 


\section{Specifications of the Designed RLSA Antennas}

Since our aim was to design RLSA antennas for Wi-Fi devices, to obtain the correct specifications for our proposed antenna, we identified specifications for a variety of $\mathrm{Wi}-\mathrm{Fi}$ antennas that are currently available in the marketplace, including microstrip antennas, dish antennas, and grid antennas. We then averaged all the specification values and categorized them into three groups, as shown in Table I.

We chose the specifications for Group 3 (the highlighted row in Table I) as the specifications for our proposed RLSA antenna because this group had the best overall specifications.

TABLE I

AVERAGE VALUES OF THE SPECIFICATIONS

\begin{tabular}{ccccc}
\hline \hline Group & $\begin{array}{c}\text { Gain } \\
(\mathbf{d B i})\end{array}$ & $\begin{array}{c}\text { Beamwidth } \\
(\text { Degree })\end{array}$ & $\begin{array}{c}\text { Bandwidth } \\
(\mathbf{M H z})\end{array}$ & $\begin{array}{c}\text { Dimensions } \\
\left(\mathbf{m m}^{\mathbf{2}}\right)\end{array}$ \\
\hline 1 & $7-9$ & $30-40$ & 700 & 12,125 \\
2 & $12-15$ & $10-30$ & 750 & 41,040 \\
3 & $16-18$ & $7-15$ & 700 & 63,700 \\
\hline \hline
\end{tabular}

Table II and Table III show the design parameters of the RLSA antenna and the feeder developed in the present study. Some of the parameters are fixed values; and the optimum values were obtained from our previous studies [13], [14]. Some of the other parameters, such as the beamsquint angle $(\Phi)$ and the number of slots $(n)$, were varied in order to obtain the best antenna model.

TABLE II

DESIGN PARAMETERS OF THE RLSA ANTENNA [13], [14]

\begin{tabular}{|c|c|c|}
\hline $\begin{array}{l}\text { Specification } \\
\text { Parameters }\end{array}$ & Symbols & Values \\
\hline Center frequency & $f$ & $5.8 \mathrm{GHz}$ \\
\hline Beamsquint angle & $\Phi$ & $\begin{array}{l}\text { Varies from } 60^{\circ} \text { to } \\
\qquad 89^{\circ}\end{array}$ \\
\hline $\begin{array}{l}\text { Wavelength inside the } \\
\text { cavity }\end{array}$ & $\lambda_{g}$ & $33.88 \mathrm{~mm}$ \\
\hline Slot length & $l$ & $0.5 \lambda_{\mathrm{g}}$ \\
\hline Slot width & $w$ & $1 \mathrm{~mm}$ \\
\hline Radius of the antenna & $r$ & $115 \mathrm{~mm}$ \\
\hline $\begin{array}{l}\text { Number of slot pairs in } \\
\text { the first ring }\end{array}$ & $n$ & $\begin{array}{c}\text { Varies from } 12 \text { to } \\
16\end{array}$ \\
\hline Cavity thickness & $d_{1}$ & $8 \mathrm{~mm}$ \\
\hline $\begin{array}{l}\text { Thickness of the } \\
\text { radiating element and } \\
\text { background }\end{array}$ & $d$ & $0.08 \mathrm{~mm}$ \\
\hline $\begin{array}{l}\text { The permittivity of the } \\
\text { cavity }\end{array}$ & $\varepsilon_{r 1}$ & 2.33 \\
\hline $\begin{array}{l}\text { Cavity material } \\
\text { Material of the }\end{array}$ & & Polypropylene \\
\hline $\begin{array}{l}\text { radiating element and } \\
\text { background }\end{array}$ & & Copper \\
\hline
\end{tabular}

TABLE III

DESIGN PARAMETERS OF THE FEEDER [13],[14]

\begin{tabular}{ccc}
\hline \hline Specs Parameters & Symbols & Values \\
\hline Height of the disc & $H$ & $3 \mathrm{~mm}$ \\
Radius of the disc & $r_{a}$ & $1.4 \mathrm{~mm}$ \\
Lower air gap & $b_{1}$ & $4 \mathrm{~mm}$ \\
Upper air gap & $b_{2}$ & $1 \mathrm{~mm}$ \\
Material of the disc & & Copper \\
Type of feeder & & SMA Feeder \\
\hline \hline
\end{tabular}

Since it is difficult to draw the RLSA antenna slots manually using simulation software, we developed a program using Visual Basic for Applications (VBA) that enabled us to draw the slots automatically. Thus, the drawing process and the simulation could be faster and more accurate.

In order to identify the best antenna model, we designed 50 models with different beamsquint angles $(\Phi)$ and a different number of slot pairs in the first ring $(n)$.

The beamsquint angles varied from $60^{\circ}$ to $89^{\circ}$; the number of slot pairs in the first ring varied from 12 to 16 (Table II).

\section{Structure of the Designed RLSA Antennas}

Figs. 1 show the structure of the 50 antenna models. It consists of a radiating element made of copper, a cavity made of polypropylene, a background element made of copper, and a feeder.

Copper was chosen as the radiating element and the background because it has good conductivity and it is affordable. Polypropylene was chosen as the dialectric material (cavity material) because it is very affordable and it has been successfully used in many previous studies [1], [10], [11], [13], [14].

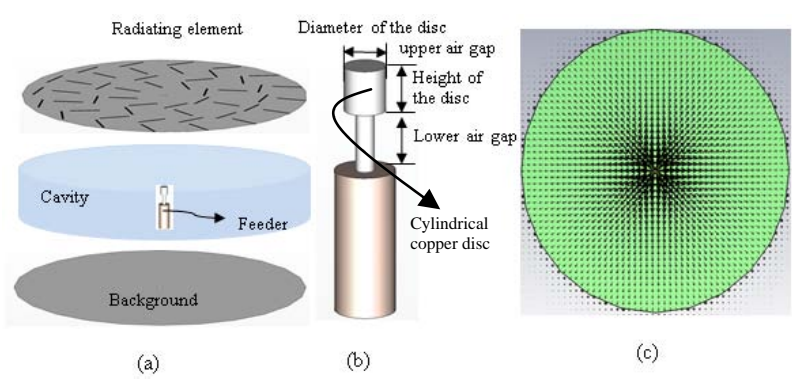

Figs. 1. (a) Structure of the RLSA antenna, (b) structure of the antenna feeder, (c) radially propagating power within the cavity. [19]

The feeder is an SMA feeder that was modified by adding a cylindrical copper disc with a height of $3 \mathrm{~mm}$, as shown in Fig. 1(b). This head functions to convert the TEM coaxial mode into the TEM cavity mode, so the electromagnetic waves will propagate in radial directions within the cavity, as shown in Fig. 1(c). The design parameters of the feeder are presented in Table III. These specifications are the best ones obtained from previous studies [13], [14].

\section{Results and Discussion}

The 50 antenna models (see Section II) were simulated, and the best model was selected and fabricated.

The best antenna model has a beamsquint angle $(\Phi)$ of $70^{\circ}$ and 14 slot pairs in the first ring $(n)$. Images of the best antenna model, the fabricated antenna model, and the fabricated feeder are shown in Figs. 2. 


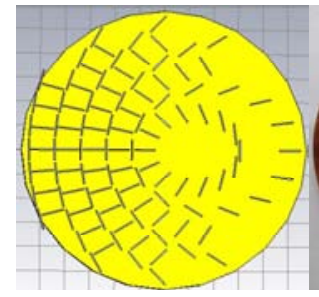

(a)

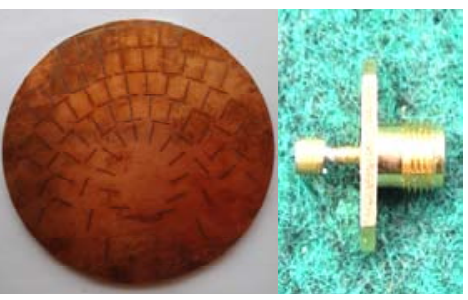

(b)

(c)
Figs. 2. (a) Best model, (b) fabricated model, (c) fabricated feeder

The radiation pattern, $\mathrm{S}_{11}$, and the gain of the fabricated model were measured using an anechoic chamber and a network analyzer. The results are shown in Figs. 3.

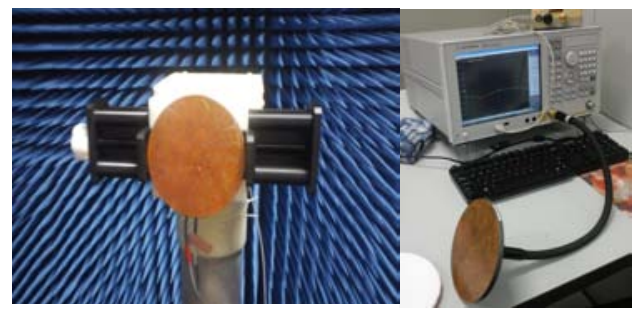

(a)

(b)

Figs. 3. (a) Measurements in an anechoic chamber, (b) measurements using a network analyzer

Fig. 4 shows the response of $S_{11}$ for both the measurements and the simulations. As seen, the antenna has a good $\mathrm{S}_{11}$ response and a wide bandwidth around 1 $\mathrm{GHz}$, which is more than enough for Wi-Fi communications. Moreover, the extreme beamsquint technique implemented in this design successfully reduced the reflection coefficient in comparison to other techniques presented in previous studies [17]-[23].

Fig. 5 shows the measured and simulated radiation pattern of the prototype antenna. As seen, the antenna has a beamwidth of $30^{\circ}$. The mainlobe direction is $65^{\circ}$ squinted from the boresight direction in the elevation direction.

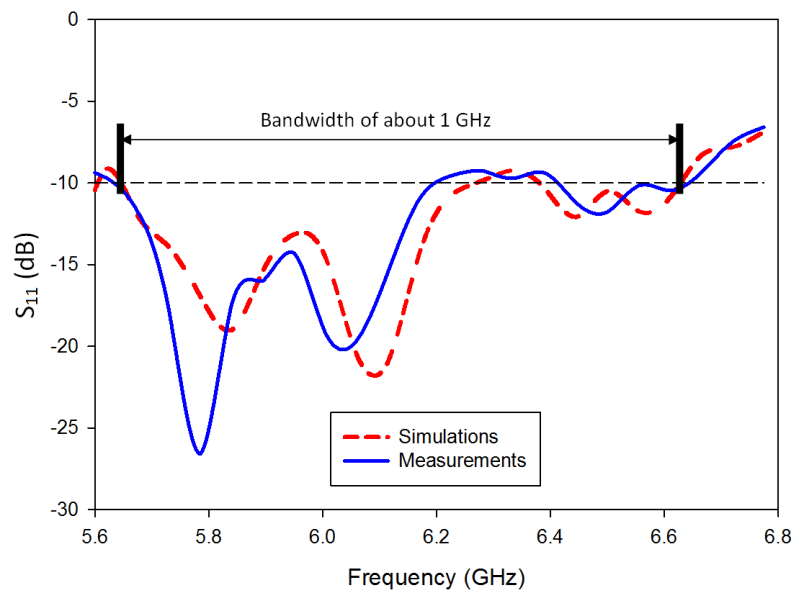

Fig. 4. Measured and simulated $\mathrm{S}_{11}$

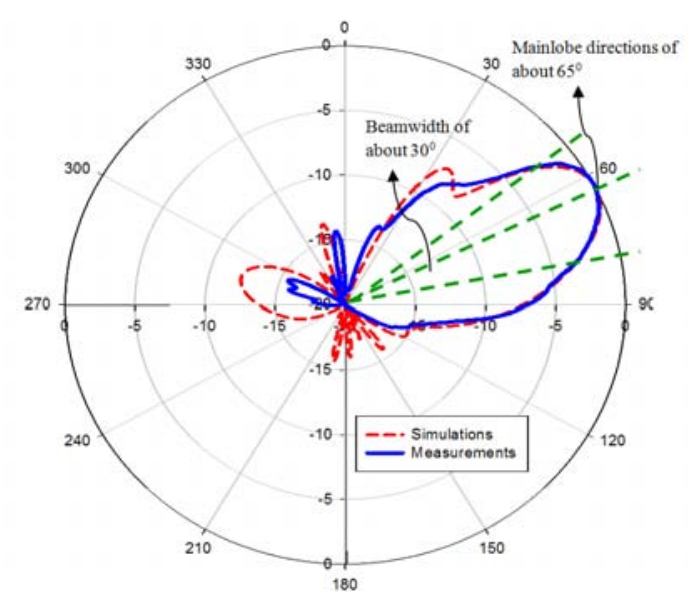

Fig. 5. Measured and simulated radiation pattern

The antenna gain $(G)$ was obtained by measuring and comparing the received signal of the antenna $\left(P_{r, \mathrm{RLSA}}\right)$ to the received signal of a reference patch antenna $\left(P_{r, \text { reference }}\right.$ antenna $)$, which has a gain $\left(G_{r, \text { reference antenna }}\right)$ of $16 \mathrm{dBi}$. The measurement results are presented in Fig. 6.

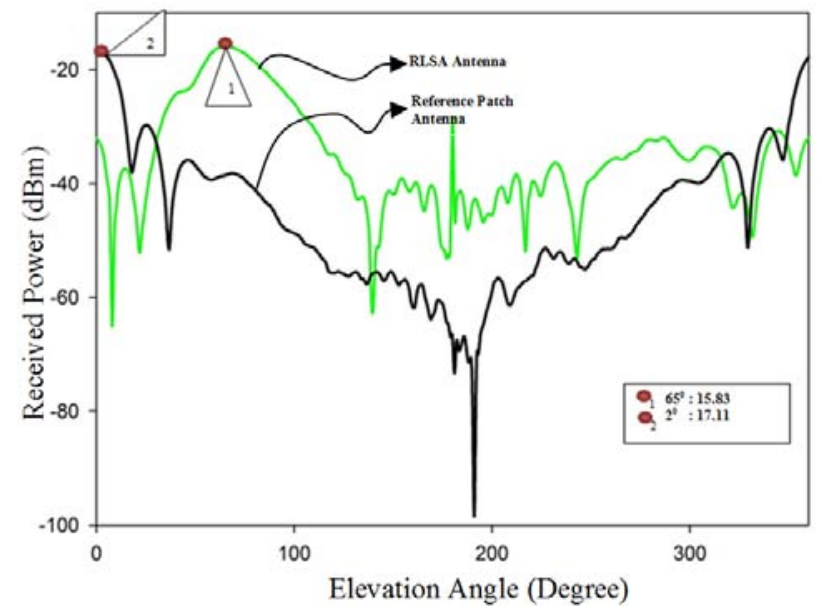

Fig. 6. Received power measurements

From the measured received power results (Fig. 6), the antenna gain was calculated as:

$$
\begin{gathered}
G=P_{r, R L S A}-P_{r, \text { reference antenna }}+G_{r, \text { reference antenna }} \\
=-15.83-(-17.11)+16 \\
G=17.28 \mathrm{dBi}
\end{gathered}
$$

The polarization of the antenna was measured by rotating the antenna $360^{\circ}$; the result is shown in Fig. 7.

As seen, the polarization of the antenna is linear.

The other measured performance parameters of the antenna are listed in Table IV.

Based on the values of the gain, the bandwidth, and the beamwidth, which are $17.28 \mathrm{dBi}, 1 \mathrm{GHz}$, and $30^{\circ}$, respectively, the performance of the RLSA antenna meets the market specification needs, as listed in Table I (Group 3). 


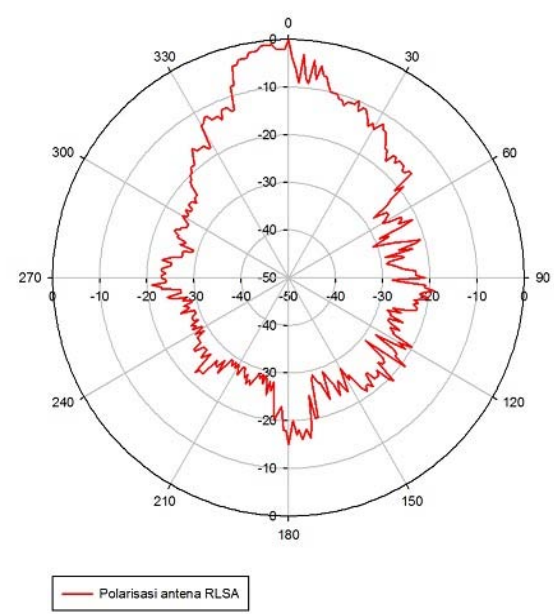

Fig. 7. Polarization measurement results for the proposed RLSA antenna

TABLE IV

PERFORMANCE PARAMETERS

\begin{tabular}{cc}
\hline \hline Performance Parameters & Values \\
\hline Gain & $17.28 \mathrm{dBi}$ \\
$3 \mathrm{~dB}$ Bandwidth & $\pm 1 \mathrm{GHz}$ \\
$3 \mathrm{~dB}$ Beamwidth & $30^{\circ}$ \\
Mainlobe-to-sidelobe Ratio & about $10 \mathrm{~dB}$ \\
Mainlobe directions & $65^{\circ}$ from the boresight direction \\
Efficiency & $-0.1635 \mathrm{~dB}$ \\
\hline \hline
\end{tabular}

As seen in Fig. 4 and Fig. 5, the simulation results are comparable to the measurement results. Any difference between the results is due to imperfections that occurred while fabricating the antenna model. The radiating element, the cavity, and the background were separated, so when they were combined during the fabrication process there was a slight shift from the correct position.

Moreover, the permittivity of the cavity was slightly increased because glue was used to attach the radiating element and the background to the cavity. Finally, soldering imperfections were observed at the head disc of the SMA feeder at the correct position.

In order to test the antenna's performance under real conditions, we built a test bed system (Fig. 8).

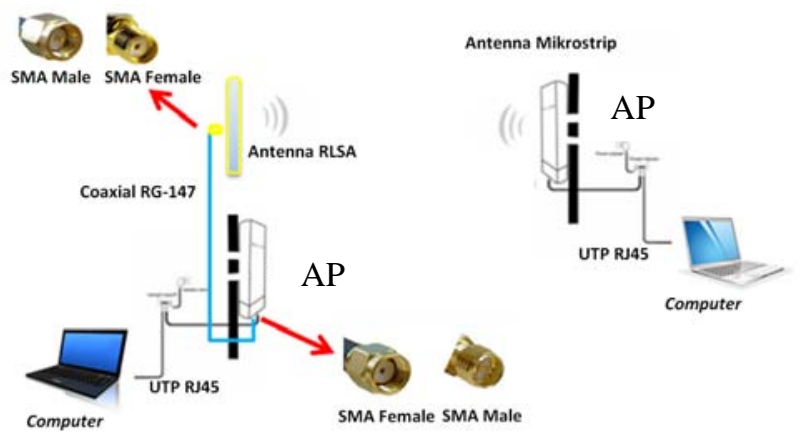

Fig. 8. Test bed system

The test bed consists of two $5.8 \mathrm{GHz}$ radio access points (APs) as transceivers; the RLSA antenna was connected to one of the transceivers, a microstrip AP antenna was connected to the other transceiver, and two computers were connected to the two APs. We conducted the test by setting up data communications between the two computers for several time points and distances. The test results show that the communications occurred without any problems, thus verifying the good performance of the antenna in a real environment.

The dimensions of the proposed RLSA antenna are $p i^{*}(115 \mathrm{~mm})^{2}=41,526 \mathrm{~mm}^{2}$. The antennas currently available in the marketplace have an average dimension of $63,700 \mathrm{~mm}^{2}$ (see Table I), which is quite a bit larger.

In terms of performance, our RLSA antenna has a gain of $18.4 \mathrm{dBi}$, a bandwidth of about $1 \mathrm{GHz}$, and a beamwidth of $29^{\circ}$. The antennas available in the marketplace have an average gain of 16-18 dB, an average bandwidth of $700 \mathrm{MHz}$, and an average beamwidth ranging from $7^{0}$ to $15^{0}$. Therefore, our proposed RLSA antenna is significantly smaller than the currently available antennas, and it has a better performance. Furthermore, based on our observation, our fabricated RLSA antenna is flat, as are microstrip antennas, so it has the potential to be another antenna option for Wi-Fi devices.

\section{Conclusion}

We designed and fabricated an RLSA antenna. Based on simulations and measurements, we found that the proposed antenna is smaller and has better performance than antennas that are currently available in the marketplace. We also tested the RLSA antenna as an antenna for Wi-Fi devices and determined that its performance was good.

\section{Acknowledgements}

We would like to thank Computer Simulation Technology Malaysia Sdn. Bhd, for granting us a temporary license to use CST STUDIO SUITETM software for one month as the simulation software in our research study. We would also like to express our appreciation to the people at the Advance Microwave Laboratory, Faculty of Electronic and Computer Engineering, Universiti Teknikal Malaysia Malaka for their assistance in conducting the antenna measurements.

\section{References}

[1] P. W. Davis, Experimental investigations into a linearly polarized radial slot antenna for DBS TV in Australia, IEEE Transactions on Antennas and Propagation, volume 45, 1997, pages 11231129.

[2] J. M. Fernández González, et al., Lightweight portable planar slot array antenna for satellite communications in x-band, IEEE Antennas and Wireless Propagation Letters, volume 10, 2011, pages 1409-1412.

[3] M. Ando, et al., Radial Line SLot Antenna For $12 \mathrm{GHz}$ Satellite TV Reception, IEEE Transactions on Antennas and Propagation, volume AP-33, 1985, pages 1347-1353.

[4] Y. Wang, et al., The investigation for a circularly polarized radial line slot antenna with low side lobes and high gain, Microwave and Millimeter Wave Technology (ICMMT), pages 1226-1227, 2012.

[5] M. F. Jamlos, et al., A beam steering radial line slot array (RLSA) 
antenna with reconfigurable operating frequency, Journal of Electromagnetic Waves and Applications, volume 24, 2010, pages 1079-1088.

[6] K. S. Bialkowski and S. Zagriatski, A dual band $2.4 / 5.2 \mathrm{GHz}$ antenna including a radial line slot array and a patch, IEEE Antennas and Propagation Society, AP-S International Symposium (Digest), pages 3095-3098, 2004.

[7] M. F. Jamlos, et al., A reconfigurable radial line slot array (RLSA) antenna for beam shape and broadside application, Journal of Electromagnetic Waves and Applications, volume 24, 2010, pages 1171-1182.

[8] T. A. R. M. F. Jamlos, M. R. Kamarudin, P. Saad, A. M. M. Dahlan, A Novel Adaptive Wi-Fi System wiht RFID Technology, Progress In Electromagnetics Research, volume 108, 2010, pages 417-432.

[9] M. F. Jamlos, et al., Adaptive beam steering of RLSA antenna with RFID technology, Progress in Electromagnetics Research, volume 108, 2010, pages. 65-80.

[10] K. S. Bialkowski and S. Zagriatski, Investigations into a dual band $2.4 / 5.2 \mathrm{GHz}$ antenna for WLAN applications, 15th International Conference on Microwaves, Radar and Wireless Communications MIKON, pp. 660-663, 2004.

[11] S. Zagriatski and M. E. Bialkowski, "Circularly polarised radial line slot array antenna for wireless lan access point," 15th International Conference on Microwaves, Radar and Wireless Communications MIKON, pp. 649-652, 2004.

[12] T. A. Rahman, et al., "A study on effectiveness of FR4 as a dielectric material for radial line slot array antenna for wireless backhaul application," $17^{\text {th }}$ Asia Pasific Conference on Communication (APCC) 2011, pp. 385-388.

[13] T. Purnamirza and T. A. Rahman, A Novel Technique in Simplifying the Fabrication Process and in Improving the Reflection Coefficient of the Linear Polarized Radial Line Slot Array (LP-RLSA) Antennas, Journal on Electromagnetic Wave and Application, volume 26, 2012, pages 535-548.

[14] T. Purnamirza, T. A. Rahman, M. H. Jamaluddin, The extreme beamsquint technique to minimize the reflection coefficient of very small aperture radial line slot array antennas, Journal of Electromagnetic Waves and Applications, vol. 26, 2012, pages 2267-2276.

[15] J. Hirokawa, et al., Matching slot pair for a circularly-polarised slotted waveguide array, IEE Proceedings H: Microwaves, Antennas and Propagation, vol. 137, pp. 367-371, 1990.

[16] J. I. Herranz, et al., Optimization of beam-tilted linearly polarized radial-line slot-array antennas, IEEE Antennas and Wireless Propagation Letters, vol. 9, 2010, pages 1165-1168.

[17] A. Akiyama, et al., Numerical optimisation of slot parameters for a concentric array radial line slot antenna, IEE Proceedings: Microwaves, Antennas and Propagation, vol. 145, pp. 141-145, 1998.

[18] A. Akiyama, et al., Design of radial line slot antennas for millimeter wave wireless LAN, in IEEE Antennas and Propagation Society, AP-S International Symposium (Digest), 1997, pp. 2516-2519.

[19] M. I. Imran, et al., An optimization of beam squinted radial line slot array antenna design at $5.8 \mathrm{GHz}$, in 2008 IEEE International RF and Microwave Conference, RFM 2008, Sabah, 2008, pp. 139-142.

[20] M. I. Imran and A. R. Tharek, Radial line slot antenna development for outdoor point to point application at $5.8 \mathrm{GHz}$ band, in $2004 R F$ and Microwave Conference, RFM 2004 Proceedings, 2004, pp. 103-105.

[21] M. I. Imran, et al., Beam squinted Radial Line Slot Array Antenna (RLSA) design for point-to-point WLAN application, in 2007 Asia-Pacific Conference on Applied Electromagnetics Proceedings, APACE2007.

[22] M. R. U. Islam and T. A. Rahman, Novel and simple design of multi layer Radial Line Slot Array (RLSA) antenna using FR-4 Substrate, in 2008 Asia-Pacific Symposium on Electromagnetic Compatibility and 19th International Zurich Symposium on Electromagnetic Compatibility, APEMC 2008, pp. 843-846.

[23] M. F. Jamlos, et al., Adaptive beam steering of RLSA antenna with RFID technology, Progress in Electromagnetics Research, volume 108, 2010, pages 65-80.
[24] Ibrahim, I. M., Rahman, T. A., Sabran, M. I., Jamlos, M. F. Comparison of polypropylene and FR4 dielectric cavity for RLSA Antenna design at $5.8 \mathrm{GHz},(2014)$ IEEE TENSYMP $2014-2014$ IEEE Region 10 Symposium, art. no. 6863032, pp. 232-234.

[25] Ibrahim, I. M., Rahman, T. A., Sabran, M. I., Jamlos, M. F. Bandwidth enhancement through slot design on RLSA performance, (2014) IEEE TENSYMP 2014 - 2014 IEEE Region 10 Symposium, art. no. 6863031, pp. 228-231.

[26] Ibrahim, I. M., Rahman, T. A., Iliya, S. Z., Sabran, M. I, Aperture slot size effect to wide band open air gap radial-line slot array performance. Microwave and Optical Technology Letters, volume 56, pp. 2974-2978, 2014.

[27] A. Mazzinghi and A. Freni, "Simultaneous Generation of PseudoBessel Vortex Modes With a RLSA," in IEEE Antennas and Wireless Propagation Letters, vol. 16, pp. 1747-1750, 2017.

[28] S. C. Pavone, A. Mazzinghi, A. Freni and M. Albani, "Wideband analysis of RLSA Bessel beam launchers based on standing and inward traveling wave aperture distributions for electromagnetic pulse generation," 2017 11th European Conference on Antennas and Propagation (EUCAP), Paris, 2017, pp. 3649-3652.

[29] S. C. Pavone, M. Ettorre, M. Albani, Transverse circular polarized bessel beam launchers for near-field applications, by using a RLSA with an inward Hankel aperture distributions, 2015 USNC-URSI Radio Science Meeting (Joint with AP-S Symposium), Vancouver, BC, Canada, 2015, pp. 170-170.

[30] S. C. Pavone, M. Ettorre and M. Albani, "RLSA Bessel beam launchers using Hankel waves," 2015 9th European Conference on Antennas and Propagation (EuCAP), Lisbon, 2015, pp. 1-5.

[31] Soliman, M., Dwairi, M., Sulayman, I., Almalki, S., A Comparative Study for Designing and Modeling Patch Antenna with Different Electromagnetic CAD Approaches, (2016) International Journal on Communications Antenna and Propagation (IRECAP), 6 (2), pp. 90-95.

[32] Manh, L., Grimaccia, F., Mussetta, M., Zich, R., A Soft Computing Hybridization Technique for Antenna Optimization, (2015) International Journal on Communications Antenna and Propagation (IRECAP), 5 (1), pp. 16-20.

[33] Allabouche, K., Mazri, T., Jorio, M., El Amrani El Idrissi, N., Comparative Analysis of Microstrip and Dielectric Resonator Antennas for UMTS Application, (2015) International Journal on Communications Antenna and Propagation (IRECAP), 5 (1), pp. 33-38.

\section{Authors' information}

${ }^{1}$ Department of Electrical Engineering,

Faculty of Science and Technology,

Universitas Islam Negeri Sultan Syarif Kasim, Indonesia.

${ }^{2}$ Faculty of Electronic and Computer Engineering,

Universiti Teknikal Malaysia Malaka, Malaysia.

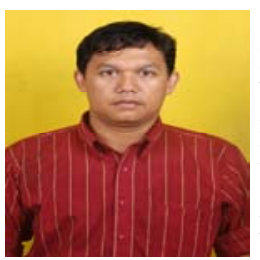

T. Purnamirza was born in Pekanbaru Indonesia on 30 Oct 1974 . He received his bachelor degree from STTTelkom Indonesia and master and doctoral degree from UTM Malaysia, all three in electrical engineering, in 2000, 2005, and 2013, respectively. He has published three books, fourteen journal papers and 4 conference papers. His research interests are antennas and propagations. Dr. Teddy Purnamirza is a senior lecturer in UIN Suska Riau Indonesia and a member of Indonesian Lecturer Accociation.

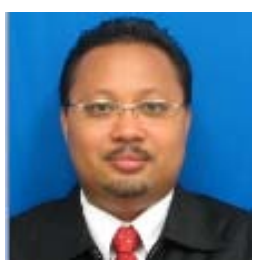

I. M. Ibrahim was born in Kedah, Malaysia on 23rd June 1976. He received his bachelor degree, master and doctoral degree from UTM Malaysia, all in electrical engineering, in 2000, 2005, and 2016, respectively. He is now serving as a Senior Lecturer in UTeM. He has published more than 30 journals and conference papers. His research interests are antennas and 
propagations. Dr. Imran is a member of IEEE Malaysia and Institute of Engineers Malaysia.

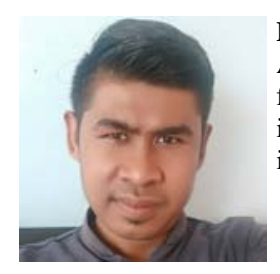

P. Prowadi was born in Riau Indonesia on 30 August 1991. He received his bachelor degree from Universitas Islam Negeri Suska Indonesia in electrical engineering in 2015. His research interests are antennas and propagations.

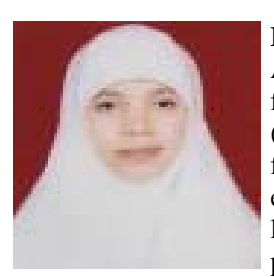

F. Amillia was born in Blitar, Indonesia on 31st August 1977. He received his bachelor degree from Universitas Muhammadiyah of Malang (UMM), Indonesia in 2001 and master degree from ITS, Indonesia in 2006, all in electrical engineering. She is now serving as senior lecturer in UIN Suska Riau Indonesia. She has published more than 10 articles in various journals and conferences. Her research interests are antenna propagations and wireless communication. 